\title{
$\varnothing$ netsafe
}

\section{netsafe.org.nz}

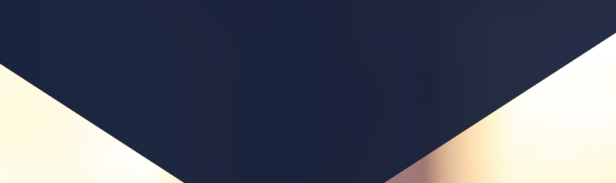

\section{Image-based sexual} abuse: A snapshot of New Zealand adults' experiences

\section{PREPARED BY DR EDGAR PACHECO, NEIL MELHUISH AND JANDY FISKE}

\section{What is this about?}

This snapshot report presents findings from a larger quantitative study about New Zealand adults' experiences of harmful digital communications. The report focuses on the prevalence of image-based sexual abuse (IBSA), and people's attitudes regarding different aspects of it. The findings described in this report are based on data collected from a nationally representative sample.

New Zealanders actively embrace digital technologies to support a range of activities from shopping and socialising to searching for information (Netsafe, 2018). Despite the opportunities and benefits, technology use (and misuse) also brings risks and challenges that could potentially result in distress and harm. In 2017 a Netsafe study found, for example, that a third of adult New Zealanders experienced an unwanted digital communication(s) ${ }^{1}$ in the prior year and, what is more, $9 \%$ reported being negatively affected by them (see Netsafe, 2018). Among the different risks and challenges people can

\section{Summary of findings}

- Overall, nearly 5\% of adult New Zealanders said they have personally experienced image-based sexual abuse (IBSA) online.

- IBSA is more common among young adults, especially those aged under 30 .

- In general, men and women were equally as likely to experience IBSA online, but the nature of the experiences differ.

- About $4 \%$ had someone threaten to share their intimate pictures or videos online. This was more common among those under 30 years old.

- Meanwhile, 3\% said their intimate content has actually been shared online. This was higher among:
- females aged 18-29
o those who do not identify as heterosexual, and
o those who identify as Asian

- The sharing of intimate content online without consent was most commonly done by an ex-partner or by a stranger.

- Perceived reasons for IBSA vary, with females indicating it is done for revenge while males say it is intended as a joke or used for extortion.

- 7 in 10 adult New Zealanders agree that those in a relationship should be aware of the risks associated with sharing intimate pictures with a partner.

- People generally lack knowledge of how the law treats cases of IBSA or where to get advice to avoid becoming a target.

- A small majority disagree that the risks of IBSA are overstated.

\footnotetext{
1 Unwanted digital communications include a range of unsolicited online experience(s) that might or might not cause distress and/or harm to the person who deals with it (e.g. spam, seeing inappropriate content, having rumours spread about oneself, being threatened).
} 
experience online are incidents related to IBSA $^{2}$, an umbrella term that encompasses a range of overlapping behaviours and experiences - from "upskirting", "sextortion", and recording of sexual assaults to "sexual voyeurism" and "revenge porn" (see McGlynn \& Rackley, 2016; Powell, Henry, \& Flynn, 2018). These non-consensual practices, which often seek to exert coercion or abuse, are not a new phenomenon. Neither are they a behaviour exclusively mediated by technology. In the past, prior to the inception of digital technologies, street posters and/or letterbox drops were used as a means for malicious practices (Powell et al., 2018). Nowadays, however, technology not only mirrors different experiences of everyday life but also magnifies and/or makes them more visible (Boyd, 2014). This is the case in distressing and potentially harmful practices such as IBSA.

While IBSA-related behaviours have attracted news media attention as well as legal discussions and interventions (DeKeseredy \& Schwartz, 2016) ${ }^{3}$, very little is known about people's experiences of this phenomenon (Powell et al., 2018). This report is the first attempt to explore the extent and nature of IBSA in New Zealand.

As the Approved Agency under the Harmful Digital Communications Act 2015 (the Act), Netsafe seeks to provide agencies, support services, and the public with research-based evidence to better understand this phenomenon and inform the development of services and resources that can help those personally targeted with IBSA to effectively address its potential negative impact.

\section{What we know so far}

Not only is research on the prevalence of IBSA limited, but also the few available studies have applied different research designs and/or definitions of IBSA. As a result, measures are difficult to compare across studies.

In Australia, for example, a study of 16- to 49year-olds conducted in 2016 (see Henry, Powell, \& Flynn, 2017) found that over 1 in 5 survey participants (23\%) had experienced at least one of three forms of image-based sexual abuse at some point in their lives. The findings regarding these specific forms of IBSA show that $20 \%$ of participants indicated that sexual or nude content was taken without their consent, $11 \%$ said that intimate content was shared without permission, and $9 \%$ reported that they were threatened with the sharing of sexual content of theirs. Other relevant findings of the study reveal that males and females were equally likely to report being the subject of IBSA, and that young adults (aged 16-29) and those who identify as nonheterosexual were more likely to be targeted.

Another study requested by Australia's eSafety Commissioner (2017) asked those aged 15 and over about their personal experiences of IBSA. The study found that 1 in 10 had nude or sexual content shared without consent. The study also uncovered that younger adults, indigenous Australians, and those who identified as non-heterosexual were more likely to experience this form of IBSA. However, in contrast to a previous Australian study (Henry et al., 2017), women were more likely to experience IBSA compared to men.

Meanwhile, a lower prevalence of IBSA has been reported in the United States (see Lenhart, Ybarra, \& Price-Feeney, 2016) where an overall $4 \%$ of respondents aged $15+$ said they have been targeted. The study found that $3 \%$ of participants have had someone threaten

\footnotetext{
2 Our working definition of IBSA is provided in the 'What we did' section of this report.

3 In New Zealand incidents of image-based sexual abuse can be an offence under the Harmful Digital Communications Act 2015. See http://www.legislation.govt.nz/act/public/2015/0063/latest/whole.html\#DLM5711838
} 
to post nude or nearly nude photos or videos of them online while $2 \%$ indicated that someone actually shared a photo of them online without their permission (Lenhart et al., 2016). The findings of this study also reveal that young people (aged 15-29), in particular young women, were more likely to report being a target of IBSA.

\section{A similar trend of Iow IBSA occurrence has been described in New Zealand. A study conducted by Netsafe in 2017 about online risks and harm found that $3 \%$ of adult New Zealanders had intimate images and/or recordings shared on the internet without their permission (Netsafe, 2018). The study did not explore perceived reasons for it, who shared the content, and/or the extent of the impact of this online experience.}

In a similar manner, nationally representative studies on teenagers (aged 14-17) conducted in Australia and New Zealand depict a low prevalence of the sharing of nudes without consent in the prior year. In Australia, the eSafety Commissioner's online survey ${ }^{4}$ found that around $5 \%$ of all teens either shared an image of someone else online or had shown it to others on their device. Also, around 9 in 10 Australian teens agreed that sharing a nude picture or video of someone without their consent was illegal and people should not do it. In another Australia-based study (see Crofts, Lee, McGovern, \& Milivojevic, 2015) 20\% of young people said they have showed another person an image without the person's consent. In the same study just $6 \%$ indicated sending an image to another person without consent. Meanwhile, in New Zealand, a Netsafe (2017) study found that only $3 \%$ of teens surveyed had shared online nude or nearly nude images or videos of someone else without consent in the previous 12 months. However, teens' perceptions about others engaging in this behaviour was higher (14\%). While these studies on teenagers provide useful insights, they were conducted in the context of 'sexting' rather than the nature and extent of IBSA.

\section{What we did}

We conducted a survey-based study with 1,001 adult New Zealanders. Fieldwork took place between 30 May and 1 July 2018. The survey looked at the extent of online risks and harmful digital communications in $\mathrm{New}$ Zealand. This report only describes the findings regarding questions on image-based sexual abuse.

The objectives of the IBSA questionnaire were to gauge prevalence among adult New Zealanders: both self-reported personal experiences and involvement with this behaviour. It also sought to explore participants' level of agreement with IBSArelated issues.

Our working definition of IBSA was informed by previous research on the topic conducted overseas:

\section{Image-based sexual abuse is the distribution or threat to distribute any intimate or sexual digital communication (e.g. picture or video) online without consent.}

By intimate or sexual we mean digital pictures or videos that depict a person nude or seminude (e.g. in underwear). The content might have been taken and shared with someone consensually. However, this does not mean that consent is granted to share/distribute the content with others through tools such as mobile devices, social media, websites, and online forums. The scope of IBSA for this study also includes content that has been altered to make it look sexual (Powell et al., 2018).

As our working definition describes, following the approach of Lenhart et al. (2016), this research centred on two aspects: peoples' experiences of threats, and the sharing of their intimate content without consent. Other similar IBSA studies have applied definitions that focused on the sharing of content only (see eSafety Commissioner, 2017; Netsafe, 2018) or

\footnotetext{
4 See the report entitled Young People and Sexting - Attitudes and Behaviours. Research Findings from the United Kingdom, New Zealand and Australia. https://www.esafety.gov.au/about-the-office/research-library
} 
included the taking of intimate sexual content without someone's permission (see Henry et al., 2017). We did not take the former approach because the definition was too narrow and not considering the making of threats also overlooked a coercive, and potentially harmful, online behaviour. The taking of content, on the other hand, overlaps with other issues such as privacy. Also, while it might be considered ethically and morally wrong, the intention to cause distress and/or its impact on actual harm is not entirely apparent. For these reasons we did not consider this aspect.

Those who completed the questionnaire came from a representative range of backgrounds in terms of age, gender, ethnicity and region. Regarding gender, females represented 52\% of the total sample while males made up the remaining $47.7 \%$. Only $0.03 \%$ of participants identified as gender diverse. In terms of ethnicity our sample was distributed as follows: NZ European/Pākehā (71\%), Māori (11\%), Pacific (5\%), Asian (11\%), and "other" ethnicity (9\%).

Data about sexual orientation was also collected. As there were relatively few respondents who identified as gay, lesbian, bisexual, or other, these respondents were grouped as non-heterosexual $(n=62)$ to make statistically valid comparisons with heterosexual respondents. This approach is common in survey-based research.

The margin of error for this study was $+/-3.1 \%$ at a $95 \%$ confidence level on total results.

The survey findings provide general characteristics of IBSA in New Zealand. However, as the survey results show a low prevalence of IBSA, a limitation of the study is that we are unable to confidently compare findings in regard to key demographics. Thus, any description of findings in this report on the basis of demographics such as age, ethnicity or gender must be taken as indicative.

We are also aware that measuring the prevalence of IBSA faces other challenges such as participants' willingness to honestly report their personal experiences or individual judgement of what IBSA is for them, which can affect the nature of the data collected, and the interpretation and reporting of findings.

\section{What we found}

This section describes the main findings from the study. In addition, it presents some reflections from Netsafe's Contact Centre team. This team is a key part of our organisation as they directly deal with reported incidents of IBSA and provide support to those who have been targeted. We asked the Contact Centre team to reflect on the findings from the perspective of their operational and practical experience.

\section{OVERALL EXPERIENCES OF IBSA}

Of 1001 participants surveyed, a total of 49 indicated to have been threatened and/or have had personal intimate sexual content shared without consent, representing around $5 \%$ of the total sample. As Figure 1 shows, IBSA experiences were most common among young adults, particularly those aged 18-29 years old.

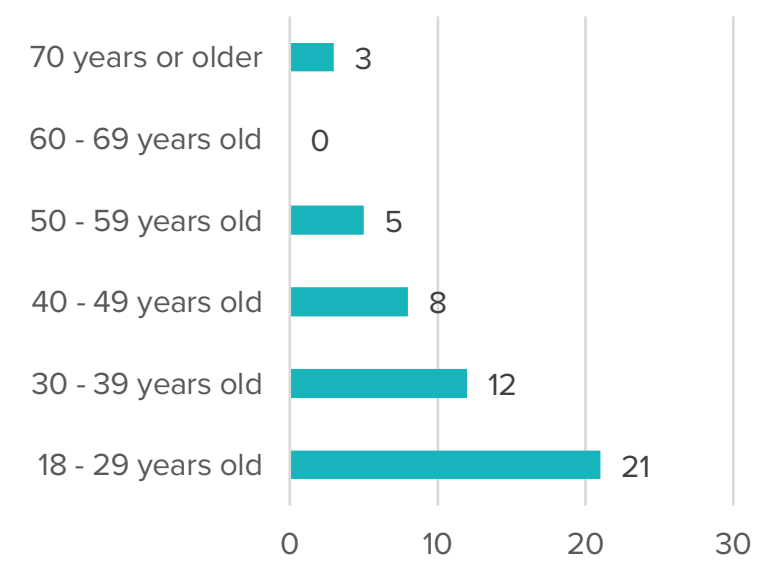

Figure 1. Number of participants who have experienced IBSA by age

Base: Respondents who had someone share or threaten to share intimate pictures/videos of them online (49). 


\section{Contact Centre reflections on gender differences}

"The finding that as many males as females were targets of IBSA was initially surprising. This is because the reports we receive about 'revenge porn' are mainly from women. However, we also deal with other types of IBSA such as 'sextortion' scams where more males than females contact us for support.

In relation to women's experiences, a typical report involves an ex-partner using intimate images or video to maintain control over them, to blackmail them, or to 'punish' them for leaving a relationship. The women contacting us in these relational-IBSA cases are often in serious distress. Sometimes the incident reported to us is part of a wider family violence situation with the real threat of physical violence.

The men contacting us about sextortion scams seem to reluctantly seek support. Finding their situation embarrassing, they commonly only report to us online and don't often elaborate on the distress they are experiencing. This could be because of the shame associated with engaging quickly in sexual activity online with strangers, and perhaps they are aware that it is risky behaviour."

There was no statistical difference regarding experiences of IBSA behaviour between males and females. Both were equally likely to experience image-based sexual abuse online.

As previously described, IBSA is defined on the basis of two behaviours: threatening to share and sharing without consent intimate content online. We asked participants about these two separately.

\section{EXPERIENCES OF BEING THREATENED} WITH IBSA

We asked participants the following question: "Has someone threatened to distribute or share online an intimate or sexual picture or video of you? Soon we will ask whether someone has actually done this." To measure prevalence and frequency our response scale included: "No"; "Yes, in the last month"; "Yes, in the last six months"; "Yes, in the last year"; "Yes, over a year ago"; and "Don't know".

Figure 2 shows aggregated responses for this question. Our findings reveal that a large majority of participants (94\%) said they have not been threatened with IBSA. Only 4\% indicated that someone had threatened to share their intimate pictures or videos online, while $2 \%$ said they "don't know".

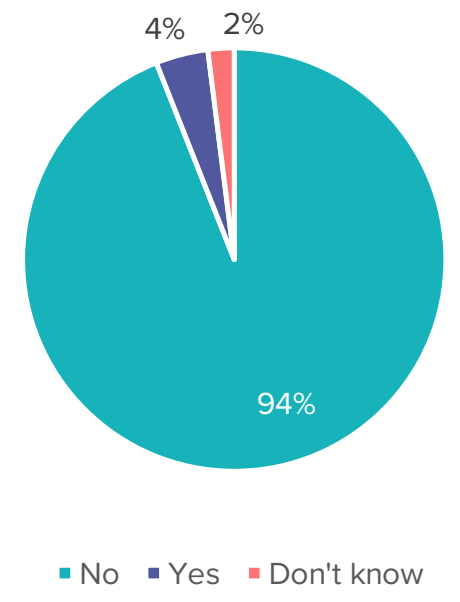

Figure 2. Self-reported experiences of being threatened with IBSA

\section{Base: All respondents (1001).}

Among those who said they were threatened with IBSA, it was equally common (4\%) for male and female respondents to be the subject of this experience.

There is also some indication that threats of IBSA were more prevalent among nonheterosexual (8\%) than heterosexual respondents (3\%) and more common among those under 30 years old (7\%). Meanwhile, threatening someone with IBSA was more common among Asian (8\%) and Māori (6\%) compared with other ethnic groups. 


\section{EXPERIENCES OF SEXUAL CONTENT} BEING SHARED WITHOUT CONSENT

We also asked participants whether someone had distributed or shared online an intimate or sexual picture or video without their consent. The measures were based on the same response scale used in the prior question: No; Yes, in the last month; Yes, in the last six months; Yes, in the last year; Yes, over a year ago; and Don't know.

Our aggregated findings also show a low prevalence of IBSA in relation to sharing or distributing sexual content without permission. Only 3\% of respondents indicated that they personally experienced this situation. A similar percentage (3\%) indicated not knowing whether this had happened to them, while the large majority (94\%) responded negatively.

Details are given in Figure 3.

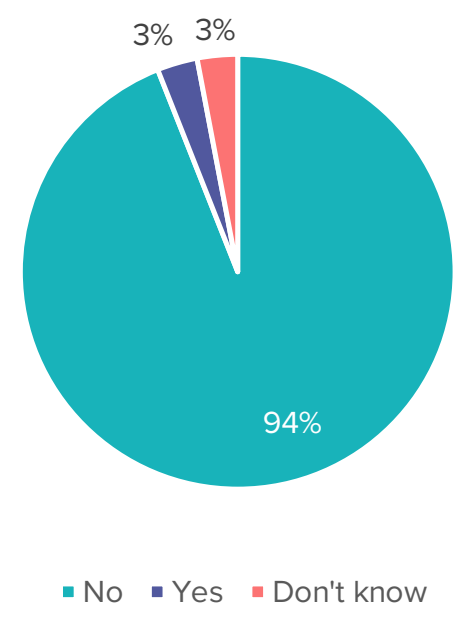

Figure 3. Self-reported experiences of sexual content shared without consent

Base: All respondents (1001).

The incidence of the sharing of their intimate content online without consent was more common among females aged $18-29$ years old (7\%). A similar pattern was identified among those who did not identify as heterosexual (10\%). Prevalence was also higher among Asian participants (7\%) and those aged under 30 years old $(7 \%)$.

\section{RELATIONSHIP WITH THE PERPETRATOR OF IBSA}

We also wanted to know who were more likely to be behind incidents of image-based sexual abuse.

Through a follow-up question, we asked all participants who previously reported to have been threatened and/or had intimate content shared online $(n=49)$ about this. The scale of responses provided to the participants was developed based on Netsafe's operational experience and prior research on the topic.

Among those who have had someone threaten to or share their intimate pictures or videos online, this was most commonly done by an ex-partner (40\%) or by someone unknown to the person (28\%). See Table 1.

Table 1. Who the perpetrator of the threatened or actual sharing of sexual consent without consent was

\section{Who was the perpetrator?}

Ex-partner

Stranger/unknown

Family member $5 \%$

Friend I know face-to-face $5 \%$

\begin{tabular}{l|l} 
Work colleague or ex-work colleague & $5 \%$
\end{tabular}

\begin{tabular}{l|l} 
Acquaintance (someone who is part of my & $4 \%$
\end{tabular} wider peer group)

\begin{tabular}{|l|c|}
\hline Someone I have only met online & $3 \%$ \\
\hline Intimate partner & $2 \%$ \\
\hline Prefer not to say & $2 \%$ \\
\hline Other & - \\
\hline Don't know & $6 \%$ \\
\hline
\end{tabular}

Base: Respondents who had someone share or threaten to share intimate pictures/videos of them online (49).

We found some gender differences but, as previously highlighted, these insights must be taken as indicative due to the small sample sizes. Having said this, our data reveal that among females, the person who threatened to or shared their intimate pictures/videos was, in most cases, an ex-partner, or to a lesser extent 
a stranger. For males, on the other hand, it was more common for the person to be a stranger, or someone they know well (such as a family member, friend or colleague).

\section{PERCEIVED REASON FOR BEING TARGETED WITH IBSA}

This group of participants was also asked to indicate the primary reason that motivated that person to share/threaten to share an intimate or sexual picture of them. To answer this question, participants were provided with a list of twelve potential reasons including "as a joke", "get revenge" and "increase their social standing".

Overall, participants' perceived reasons varied. The most common motives for IBSA were: as a joke (19\%), to get money (17\%), revenge (14\%), or to gain control (12\%). Further details are given in Table 2.

Table 2. Perceived reasons behind experiences of IBSA

\begin{tabular}{|c|c|}
\hline Perceived reason & $\%$ \\
\hline As a joke & $19 \%$ \\
\hline To get money from you & $17 \%$ \\
\hline Get revenge or get back at you & $14 \%$ \\
\hline Control you & $12 \%$ \\
\hline $\begin{array}{l}\text { Involuntary event (e.g. released by accident, } \\
\text { account was hacked) }\end{array}$ & $8 \%$ \\
\hline Humiliate you & $7 \%$ \\
\hline Threaten or intimidate you & $5 \%$ \\
\hline For sexual thrill/pleasure & $3 \%$ \\
\hline Increase their social standing & $3 \%$ \\
\hline To get more images or videos from you & - \\
\hline Other (please explain) & - \\
\hline Don't know & $12 \%$ \\
\hline
\end{tabular}

Based: Respondents who had someone share or threaten to share intimate pictures/videos of them online (49).

Our data indicate that for women the most common reasons for IBSA were for revenge, to threaten/intimidate, and for the other person to increase their social standing. For males, on the other hand, IBSA was intended as a joke or used for extortion.

\section{ENGAGEMENT IN CONDUCTING IBSA}

All participants were asked whether they have engaged in IBSA behaviour in the last 12 months. Our measure used the following scale: "never", "once", "a few times (2-4)", "many times (5 or more)", and "I don't know".

Overall, only 14 people (about 1\%) said they have shared intimate recordings of someone else without their consent.

Then we asked these participants to specify their relationship with the person whose intimate content was shared without permission. Of these 14 people, 5 said it was a friend.

\section{LEVEL OF AGREEMENT WITH IBSA- RELATED ISSUES}

The last part of the survey included six statements related to IBSA issues. We wanted to know participants' level of agreement with these statements. A Likert scale was used to measure their responses: "strongly disagree", "disagree", "neither agree nor disagree", "agree", "strongly agree", and "unsure". Table 3 presents the aggregated findings.

Regarding whether those in a relationship should be aware of the risks associated with sharing intimate pictures with a partner, a large majority (7 in 10) agreed with the statement. Older participants aged $50+$ tended to agree more with this statement. No differences were found in terms of gender.

Just over half of the participants (56\%), on the other hand, considered that sharing intimate content is the responsibility of the person who releases it. Males tended to agree more with this statement than females.

Meanwhile, a significant percentage of adult New Zealanders (35\%) lack knowledge of how the law treats cases of IBSA (35\%). Males 
tended to agree more with this statement than females.

Over a quarter of respondents $(27 \%)$ indicated lacking knowledge about where to get advice to avoid being the target of IBSA. This was higher among Asian participants compared to other ethnic groups.

Over 4 in 10 participants (45\%) considered that online providers, such as social media platforms, are doing enough to prevent cases of IBSA.

Finally, 6 in 10 disagree that the risks of IBSA are overstated. However, among those who agree, there were more males than females.

Table 3. Participants' agreement with IBSA-related issues

\begin{tabular}{|c|c|c|c|}
\hline Statement & Agree & Disagree & Unsure \\
\hline $\begin{array}{l}\text { People in a } \\
\text { relationship should } \\
\text { know of the risks of } \\
\text { having any intimate or } \\
\text { sexual pictures or } \\
\text { videos stored or } \\
\text { shared with a (ex) } \\
\text { partner in the first } \\
\text { place. }\end{array}$ & $71 \%$ & $8 \%$ & $4 \%$ \\
\hline $\begin{array}{l}\text { Posting/sharing of } \\
\text { intimate pictures or } \\
\text { videos is the } \\
\text { responsibility of the } \\
\text { person who releases } \\
\text { it. }\end{array}$ & $56 \%$ & $17 \%$ & $9 \%$ \\
\hline $\begin{array}{l}\text { I understand how well } \\
\text { New Zealand law } \\
\text { addresses cases of } \\
\text { image-based sexual } \\
\text { abuse. }\end{array}$ & $18 \%$ & $35 \%$ & $16 \%$ \\
\hline $\begin{array}{l}\text { Online providers, } \\
\text { such as social media } \\
\text { platforms, are doing } \\
\text { enough to prevent } \\
\text { cases of image-based } \\
\text { sexual abuse. }\end{array}$ & $14 \%$ & $45 \%$ & $2 \%$ \\
\hline $\begin{array}{l}\text { I know where to get } \\
\text { the advice I need to } \\
\text { avoid becoming a } \\
\text { victim of image-based } \\
\text { sexual abuse. }\end{array}$ & $34 \%$ & $27 \%$ & $11 \%$ \\
\hline $\begin{array}{l}\text { The risks of image- } \\
\text { based sexual abuse } \\
\text { are overstated. }\end{array}$ & $12 \%$ & $59 \%$ & $9 \%$ \\
\hline
\end{tabular}

Base: All respondents (1001).

\section{Contact Centre reflections on victim- blaming}

"The finding that most people agree victims of IBSA should be aware of the risks associated with sharing intimate content is interesting as it reflects an assumption we see in our practice: you should know the risks and therefore shouldn't have shared such content in the first place.

What we commonly find in cases of relational-IBSA is that supporting agencies and individuals (mainly family and friends) often insinuate or directly blame the victim. They report being told 'they shouldn't have shared', and they should 'get off social media' or 'get off the internet' entirely. This has an impact. Those targeted often tell us they were left 'feeling humiliated' or 'not heard', and that those providing support 'don't care' or 'don't understand'. This can lead towards a lack of trust in support agencies which results in less engagement and more difficulty ascertaining exactly what has occurred.

It is interesting to compare this with the 'sextortion' cases reported to us where contrastingly those targeted do not typically recount similar experiences."

\section{Concluding remarks}

This report has presented a snapshot of the extent of IBSA in New Zealand. The findings describe the experiences of adult $\mathrm{New}$ Zealanders based on data collected from a nationally representative survey.

An interesting finding of this study is the low prevalence of IBSA reported by adult New Zealanders. As previously described, about $5 \%$ of participants indicated they have been threatened and/or have had personal intimate or sexual content shared without consent. This finding is not significantly different from the 
results of our 2017 Annual Population Survey, which found 3\% of adult participants had intimate images and/or recordings shared on the internet without their permission (see Netsafe, 2018). Neither does our finding differ from a similar American study (Lenhart et al., 2016) that found $4 \%$ of respondents experienced IBSA.

However, the finding contrasts with results from some Australia-based studies (see eSafety Commissioner, 2017; Henry et al., 2017). An explanation for the differences might be the age range of the samples in the studies. In our research, participants were all adults, aged $18+$, while the Australian studies focused on young adults or included teenage respondents. Another explanation might be, as previously described, the definitions of IBSA used in the studies.

On the other hand, there seems to be a general perception that IBSA is "on the rise" 5 However, this study does not provide evidence to support or refute that claim. Further longitudinal research might help to gauge whether the prevalence of IBSA has increased or reduced over the years.

Also, despite the low prevalence of IBSA in New Zealand, we acknowledge the negative impact that this phenomenon can exert on those targeted with it. Our operational experience - as the Approved Agency under the Act - shows us that IBSA can be a distressing and harmful experience. Further, IBSA incidents are among the most common criminal offenses charged under the Act since its implementation ${ }^{6}$. In the same vein, prior research supports claims about the negative impact of IBSA (Bates, 2017; Short, Brown, Pitchford, \& Barnes, 2017).

On the other hand, the findings of this study describe some patterns that are consistent with international research. In this sense, our results support existing evidence (see eSafety Commissioner, 2017; Henry et al., 2017;
Lenhart et al., 2016) which shows that IBSA is a phenomenon more commonly experienced by young people. Also, although males and females are, overall, equally likely to experience IBSA, there are interesting differences regarding people's gender and age. For example, similar to the findings of Lenhart et al. (2016), the sharing of nude or semi-nude content without permission is more likely to have happened to young females. Likewise, our results regarding people's perceived reasons for being targeted with IBSA, and the relationship with the person who threatened or shared content without consent, provide useful insights to better understand the nature of IBSA in New Zealand. For instance, a joke that got out of control is a significant reason explaining IBSA among males in our results. However, we believe that further research is needed, especially more contextual inquiry. The use of qualitative techniques in future research has the potential to make a valuable contribution in this respect.

Finally, an interesting finding is that most participants (7 in 10) agree that those in a relationship should be aware of the risks associated with sharing intimate pictures with a partner. This sort of view seems to reflect what some call a culture of victim blaming (Felson \& Palmore, 2018; Szalavitz, 2018). Research on sexual assault suggests, for example, that the tendency of shifting blame to the victim affects judgements of incidents as perpetrators are less likely to be seen as responsible (Bieneck \& Krahé, 2011; Schuller \& Hastings, 2002). In the context of IBSA, shifting blame or responsibility to the person targeted can also raise barriers to seeking help or reporting incidents to support services and agencies (Diemer, Powell, \& Webster, 2018). This seems to be consistent with our operational experience. While this is an interesting finding, the dynamics and extent of victim blaming in New Zealand and in the context of IBSA require further exploration.

\footnotetext{
5 See for instance http://www.stuff.co.nz/life-style/life/8958936/The-rise-of-revenge-porn and https://www.nzherald.co.nz/lifestyle/news/article.cfm?c_id=6\&objectid=11888945

6 See https://www.nzherald.co.nz/nz/news/article.cfm?c_id=1\&objectid=12133500
} 


\section{What's next?}

Based on this study's findings and prior IBSA research, Netsafe has prepared information and resources to support people facing IBSA. We also recently released our awarenessraising Don't Be a Nick campaign aimed at young New Zealand adults. See:

https://netsafe.org.nz/image-based-abuse

https://netsafe.org.nz/dont-be-a-nick

\section{References}

Bates, S. (2017). Revenge porn and mental health: A qualitative analysis of the mental health effects of revenge porn on female survivors. Feminist Criminology, 12(1), 22-42. https://doi.org/10.1177/1557085116654565

Bieneck, S., \& Krahé, B. (2011). Blaming the victim and exonerating the perpetrator in cases of rape and robbery: Is there a double standard? Journal of Interpersonal Violence, 26(9), 1785-1797. https://doi.org/10.1177/0886260510372945

Boyd, D. (2014). It's complicated: The social lives of networked teens. New Haven: Yale University Press.

Crofts, T., Lee, M., McGovern, A., \& Milivojevic, S. (2015). Sexting and young people. New York: Palgrave Macmillan.

DeKeseredy, W. S., \& Schwartz, M. D. (2016). Thinking sociologically about image-based sexual abuse. Sexualization, Media, \& Society, 2(4), 237462381668469. https://doi.org/10.1177/2374623816684692

Diemer, K., Powell, A., \& Webster, K. (2018). Four in ten Australians think women lie about being victims of sexual assault. Retrieved December 11, 2018, from https://theconversation.com/four-in-tenaustralians-think-women-lie-about-beingvictims-of-sexual-assault-107363

eSafety Commissioner. (2017). Image-based abuse. National survey - Summary report. Retrieved April 24, 2018, from https://www.esafety.gov.au/image-basedabuse/about/research

Felson, R. B., \& Palmore, C. (2018). Biases in blaming victims of rape and other crime. Psychology of Violence, 8(3), 390-399. https://doi.org/10.1037/vio0000168
Henry, N., Powell, A., \& Flynn, A. (2017). Not just "Revenge Pornography": Australians' experiences of image-based abuse: A summary report. Retrieved May 30, 2017, from https://www.rmit.edu.au/content/dam/rmit/doc uments/college-of-design-and-socialcontext/schools/global-urban-and-socialstudies/revenge_porn_report_2017.pdf

Lenhart, A., Ybarra, M., \& Price-Feeney, M. (2016). Nonconsensual image sharing. Retrieved May 7, 2018, from https://datasociety.net/pubs/oh/Nonconsensu al_Image_Sharing_2016.pdf

McGlynn, C., \& Rackley, E. (2016). Image-based sexual abuse: More than just "revenge porn." Retrieved April 24, 2018, from https://www.birmingham.ac.uk/Documents/col lege-artslaw/law/research/bham-law-spotlightIBSA.pdf

Netsafe. (2017). Teens and "sexting" in New Zealand: Prevalence and attitudes. Wellington, New Zealand. https://doi.org/10.2139/ssrn.3128598

Netsafe. (2018). Harmful digital communications in New Zealand: Annual Population Survey 2017. Wellington, New Zealand. https://doi.org/10.2139/ssrn.3128121

Powell, A., Henry, N., \& Flynn, A. (2018). Imagebased sexual abuse. In Walter S. DeKeseredy \& M. Dragiewicz (Eds.), Routledge Handbook of Critical Criminology (pp. 305-3015). Routledge. Retrieved from http://ebookcentral.proquest.com/lib/monash/ detail.action?docID=5306762

Schuller, R. A., \& Hastings, P. A. (2002). Complainant sexual history evidence: Its impact on mock jurors' decisions. Psychology of Women Quarterly, 26(3), 252-261. https://doi.org/10.1111/1471-6402.00064

Short, E., Brown, A., Pitchford, M., \& Barnes, J. (2017). Revenge porn: Findings from the harassment and Revenge Porn (HARP) Survey: Preliminary results. Annual Review of Cybertherapy and Telemedicine, 161-167. Retrieved from http://www.arctt.info/volume15-summer-2017

Szalavitz, M. (2018). Why we're psychologically hardwired to blame the victim. Retrieved December 11, 2018, from https://www.theguardian.com/usnews/2018/feb/27/victim-blaming-sciencebehind-psychology-research 
IMAGE-BASED SEXUAL ABUSE: A SNAPSHOT OF NEW ZEALAND ADULTS' EXPERIENCES

Wellington, New Zealand, January 2019

www.netsafe.org.nz

research@netsafe.org.nz

Recommended citation: Netsafe. (2019). Image-based sexual abuse: A snapshot of New Zealand adults' experiences. Retrieved from: https://www.netsafe.org.nz/image-based-sexual-abuse-survey-2019

ISBN: 978-0-473-46717-3

https://creativecommons.org/licenses/by-nc-sa/4.0/legalcode.mi [Te Reo Māori] 